\title{
Euthanasia, disthanasia or orthothanasia?
}

\author{
Eutanásia, distanásia ou ortotanásia?
}

Why do the subjects euthanasia, disthanasia and orthothanasia call such attention and cause so much discussion among us? It is clear that the sanctity of life and its constitutional protection are already very convincing answers. However, I would like to mention other paradigms. The increased prevalence of chronic-degenerative diseases among us is a fact and, paradoxically, there is lack of adequate palliative care making that most human populations are deprived of these care units. Added to this scenario, we find huge barriers to offer human and adequate care to terminal patients, from the failure in qualifying professionals, to health system deficiencies, to the interpretation of bioethics and biolaw.

Faced to this context, it is paramount to distinguish euthanasia ("to kill after being asked to, to accelerate death"), assisted suicide ("to help committing suicide") and disthanasia ("slow death with lots of suffering"), from orthothanasia ("natural, correct death"). The first two concepts are interpreted as crimes in our country, regulated by article 121 of the penal code as homicides. The search for these means is closely related to fear of pain, loneliness or family abandonment, and by rejection of the coldness and impersonality permeating the assistance to many of our end-of-life counterparts. So, we once more understand the mandatory indication of palliative, correct and safe care in a society which shall not fail to the point of having its participants asking for the right of dying because they are not cared for. Palliative care is a powerful alternative to the proposals of legalizing euthanasia or assisted suicide.

Disthanasia seems to have free flow through our hospitals and goes unnoticed. In fact, it is a useless treatment, cultivated by a Western society which values saving the life at any cost and submits patients to therapies which, in summary, do not prolong life, but rather the death process. Cure is impossible, expected benefit is meanest, the effect is noxious. It is the therapeutic obstinacy or the medical futility.

Among this number of concepts emerges orthothanasia which, differently from euthanasia is sensitive to the death humanization process and to pain relief. It does not tolerate disproportionate treatments, does not incur in abusive delays, it faces death at the right time, without falling in the disthanasia trap. It generates the possibility of discussing with people the difference between curing and treating, between maintaining life when this is the right procedure or signaling death when it time arrives. Death then may be understood as part of life, offering experiences which may be enriching and unforgettable. However, in spite of this clarity, orthothanasia in our country has generated much discussion. It is an atypical approach according to the Penal Code because it is not the cause of death, since the dying process has been already installed. On the other hand, it is advocated after the irreversibility of a pathological condition. The Federal Council of Medicine has regulated with Resolution 1805/06, the medical approach faced to the desire of the patient or legal representative of limiting or withdrawing procedures and treatments prolonging the life in terminal phase, in cases of severe or incurable diseases. This resolution was suspended by request of the Public Prosecutor's Office in 2007. The medical class resented but finally the Public Prosecutor's Office request was considered groundless putting a full stop in the action and bringing back the practice of orthothanasia, which is a landmark in the valuation of human beings autonomy and well-being.

Concluding, this journal and our society are proud of bringing such subjects to discussion and of being able to generate scientific inputs which may minimize the suffering or our fellow creatures.

João Batista Santos Garcia

President Brazilian Society for the Study of Pain (2011-2012) Assistant Professor Doctor, Federal University of Maranhão (UFMA) Responsible for the Pain Service of the University Hospital UFMA and for the Pain Service of the Maranhão Cancer Institute. 